\title{
Advances in the Treatment of Breast Cancer-Emphasis on fertility preservation- A Case Report
}

\author{
Kochar Kaur Kulvinder ${ }^{*}$, Allahbadia $\mathrm{G}^{2}$, Singh $\mathrm{M}^{3}$, SK Bhatia ${ }^{4}$ and Singh $\mathrm{G}^{4}$
}

${ }^{1}$ Scientific Director, Dr. Kulvinder Kaur Centre for Human Reproduction, Jalandhar, Punjab, India

${ }^{2}$ Scientific Director, Rotunda-A Centre for Human reproduction, Mumbai, India

${ }^{3}$ Consultant Neurologist, Swami Satyanand Hospital, Jalandhar, Punjab

${ }^{4}$ Embryologist, Dr. Kulvinder Kaur Centre for Human Reproduction, Jalandhar, Punjab, India

${ }^{*}$ Corresponding author: Kochar Kaur Kulvinder, Scientific Director, Dr. Kulvinder Kaur Centre for Human Reproduction, 721, G.T.B. Nagar, Jalandhar, Punjab, India 144001, Fax: 91-181-4613422, Tel: 91-1819501358180,91-181-4613422,E-mail: kulvinder.dr@gmail.com

Citation: Kochar Kaur Kulvinder, Allahbadia G, Singh M, SK Bhatia, Singh G (2017) Advances in the Treatment of Breast Cancer-Emphasis on fertility preservation-A Case Report. J Gynaecol Res 3(1): 103. doi: 10.15744/2454-3284.3.103

\section{Received Date: November 21, 2016 Accepted Date: May 23, 2017 Published Date: May 24, 2017}

\begin{abstract}
With the recent advances in breast cancer treatment the 5 year survival rates have increased significantly with overall $20 \mathrm{yrs}$ survival in developed countries like USA. With further improvement being designed in the treatment of breast cancers with more and more sophisticated models to study breast cancer in human beings using the modern microfluidic models one expects more and younger breast cancer survivors to be needing fertility treatments. Here we review the modern advances in breast cancer treatments and the need for emphasizing on fertility preservation before starting any chemotherapeutic or other management as recommended by both ASO and ASRM. We further discuss the methods of fertility preservation in such young breast cancer patients or models without affecting there 5 years survivals we further report a case of HER2 positive breast cancer patient receiving multiple chemotherapeutic agents followed by radiotherapy where such treatment was not even discussed in a patient of primary infertility before starting treatment like chemotherapy and radiotherapy even in a developing country where cryopreservation of embryos or oocytes was possible just before the treatment if not preserving the ovarian tissue .
\end{abstract}

Keywords: HER2/neu positive breast; Cancer; Tranzutuzumab; Bevacizumab; Adezolizumab; Tecemotide; Lag3; Indoximod; Fertility preservation; Ivfoocyte cryopreservation

\section{Introduction}

After skin cancer breast cancer is the most common cancer in women, with breast cancer being the commonest malignancy in women of reproductive age group [1]. With the recent advances in breast cancer treatment the 5 year survival rate has increased to $89.7 \%$ in the United States [2]. With further improvements in the treatment of breast cancer and more sophisticated models one expects there to be an increased number of young women who may require fertility treatments [3-6]. "With newer methods regarding breast cancer treatment, five year survival rates are anticipated to improve as well as 20 year survival rates. Given this, there should be emphasis for the clinician to counsel on fertility preservation as many females after being treated may desire to conceive." "Here we report a case of a 40yr HER2 neu positive breast cancer patient who received Chemotherapy and Radiation treatment (CRT) a history of primary infertility which was not offered counseling regarding reproductive options.

\section{Advances in Breast Cancer Treatment}

\section{Transtuzumab}

Transtuzumab is a monoclonal antibody, which is utilized for the therapy of breast cancer which overexpresses the human epidermal growth factor receptor 2 (HER2) oncogene. This is seen in 15-30\% of breast cancers and are associated with a poor prognosis [8,9]. In $1998 \mathrm{FDA}$ approved it as a therapy to be used in combination with chemotherapy for metastatic breast cancer [10]. This was done on the basis of a phase III trial which showed that combining standard chemotherapy significantly raised time to progression, response rate, duration of response, along with overall survival in contrast to chemotherapy alone. Also there was a significant increase in disease free interval and OS [11-13]. Thus trastuzumab received FDA approval for treatment of breast cancer 
along with chemotherapy in 2006. Right now a combination of tranztuzumab and pembolizumab is being examined in phase I/II clinical trials in patients having transtuzumab resistant HER2 +ve metastatic breast cancer in a clinical trial with the identification NCTO2129516.Previously it has been shown that tranztuzumab and anti PD1 treatment are synergistic in mice [14].

\section{Vegfr}

Vascular endothelial growth factor A plays an important role in angiogenesis. The monoclonal antibody bevazumab targets it. It also increases tumor infiltrationby Tand B lymphocytes [15,16] and it is supposed to inhibit regulatory T cells (Treg cells) [17]. Bevacizumab got approved as first line treatment of metastatic breast cancer, as shown by clinical trials phase III patients who were HER2 negative and Miller et al. showed in these patients bevacizumab with paclitaxel led to marked increase in PFS and objective response rate [18].

\section{Role of MUC1}

Recently we reviewed the role of tecemotide which targets TAA MUC1, WHICH gets overexpressed along with aberrantly glycosylated in $>90 \%$ adenocarcinmas of lung and breast [19-21] There were different immunotherapies which targeted MUC1, which were assessed [22] There was no improvement in OS with tecemotide as compared to placebo but those who received concurrent chemoradiotherapy followed by tecemotide showed marked increase in survival as compared to those who received sequential CRT. Degregario et al. showed letrozole followed by tecemotide showed improvement in contrast to those who received tamoxifen [23]. Following roughly 20 months of more follow up following concurrent CRT and tecemotide had marked increase in survival [24]. Thus timing of CRT and immunotherapy remains important and monitoring immune status may be essential while designing treatment regimens where tecemotide has to be incorporated with CRT $[25,26]$.

\section{PD-L1}

Adezolizumab (MPDL3280A): Adezlizumab is an anti PD-L1 monoclonal antibody, which has shown activity in multiple advanced cancers in phase 1 clinical trials. Antibodies' Fc region is modified so that both antigen dependent cellular cytotoxicity (ADCC) and complement dependent cytotoxicity(CDD) [27] which prevents killing immune cells which also express PDL1 like activated T cells. Patients with the triple negative breast cancer cohort had an ORR of 19\%, with a PFS following 24wks [28].

\section{LAG3}

This acts as a good target for immunotherapy because it negatively regulates effector T cells [29]. It is expressed on the membranes of the activated T cells ans is up regulated on exhausted T cells [30]. Main ligand of LAG3 is MHC class II and their interaction may play a role in changing dendritic function [31]. In a phase 1 clinical trial which evaluated a combination of taxane based chemotherapy and IMP321 in women with metastatic breast cancer, a 50\% ORR was observed [32].

\section{CEA}

CEA is an oncofetal antigen .In a phase II trial reported recently,which compared treatment with PANVACTM in combination with docetaxel in contrast to docetaxel alone in 48 patients having metastatic breast cancer, increased improvement and PFS was found in patients receiving both in contrast to docetaxel alone, although result was not statistically significant it showed some beneficial effects [33]. One finds smaller relapse free intervals in breast cancer patients which overexpress CEA [34].

\section{IDO1}

The enzyme Indoleamine 2,3 dioxygenase (IDO) catabolizes the essential amino acid tryptophan and its up regulation has been found to be a mechanism for tumor cell immunoescape. Tryptophan is needed for normal $\mathrm{T}$ cell function and once depletedcan=>immune suppression [35]. The IDO1 enzyme is overexpressed in different malignancies like breast, prostate NSCLC, gastric ovarian cancer [36].

Two small moleculesI DO-1 enzyme inhibitors and a peptide based vaccine are being evaluated in clinical trials. Indoximod (1 methyl D tryptophan) combined with docetaxel is being studied in phase 1 clinical trials in solid metastatic tumors. A phase II trial of Indoximod along with docetaxel combination is used as first line treatment for metastatic breast cancer is ongoing [Clinical trials gov identifier NCT01792050] in addition to a number of other phase II studies for other cancers.

\section{Sialyl Tn-KLH}

Sialyl Tn conjugatedro keyhole-limpet Haemocyanin $\{$ SN-KLH) treated with concomitant endocrine therapy gave longer TTP and OS than KLH alone in a phase III double blinded international trial involving I 1028women with metastatic breast cancer. Further in women who received endocrine therapy those having a median or greater antibody response (titre $>1: 320$ towards ovine submaxillary mucinto the STn -KLH vaccine had significantly longer median OS than those below this titre [37]. 


\section{Fertility following Breast Ca Treatment}

It is well known that chemotherapy directly damages the ovarian follicles and thus the ovarian reserve [38-41]. With endocrine therapy indirect effects are seen .Pregnancy is contraindicated while on hormonal therapy as there is risk of teratogenicity and it hampers the ovulatory and endometrial function=>increased risk of amenorrhea for a short time. Chemotherapy may lead to amenorrhea either temporarily or permanently, with early menopause might be causing loss of ovarian reserve [40]. Various chemotherapeutic agents like cyclophosphamide (Cy) are harmful only in older women and when used in high doses [39,41,42]. Women Receiving doxorubicin along with cyclophosphamide for 4cycles there is decrease in ovarian reserve in $<20 \%$ of survivors of $<40 \mathrm{yrs}$ age, in contrast to $20-80 \%$ experiencing loss of ovarian reserve who were older [43]. As compared to those receiving first Cy and then docetaxel had highest loss of ovarian reserve 12 months following treatment in contrast to concurrent docetaxel plus Cy (58\%) and 38\% in doxorubicin and docetaxel [44]. In another study no statistically significant differences of amenorrhea were found between transtuzumab or dose dense regimens every 2weeks [45]. Early referral allows patients to use fertility preservation options in the form of use of cryopreservation cycles and chemotherapy and when possible multiple FP cycles. With earlier referral multiple cycles give advantage for greater oocytes/embryos getting cryopreserved [46,47], without delay in initiation of systemic therapy. Therefore it is important that breast surgical oncologist imparts knowledge of fertility information at initial visit [48]. Both as per Guidelines of American Society of clinical oncology as well as those of ASRM it is mandatory [42,49]. We report a case report where such recommendations were not followed in an infertile woman and thus forced to use donor egg ivf.

\section{Case Report}

A 40 year old patient reported in November 2013 with history of primary infertility 13years along with history of having been operated for breast cancer in 2006. Operation notes showed she had a breast conservative surgery with axillary clearance (BCS with AC). Histopathological report revealed a tumour size of $2 \mathrm{~cm} \mathrm{x} 1.5 \mathrm{~cm} \mathrm{x} 1 \mathrm{~cm}$. All surgical margins were positive for tumour grade III. Axillary clearance showed 5out of 24 lymph nodes being positive for tumor 5/24. Hormone Receptor study showed ERnegative PR -negative, HER2/neu-was strongly positive. Metastasis study was negative making it STAGE III T1c, pN2M0. Patient was given 6 cycles of CEP cytotoxic chemotherapy (CCT-CEP regimen at 3 weekly intervals-injection cyclophasphamide150mg, epirusicin-150mg, inj 5fluorouracil (5-FU) 150mg. After completion of CEP cytoxic CT, she was given 28 fractions of external beam radiotherapy and has been on follow up regarding breast cancer spread. Since she had completed 5 year survival period she was taken up for fertility treatment after thoroughly working her up for cancer status and as expected with her receiving heavy chemotherapy and radiotherapy she was a candidate for donor egg ivf with ovaries showing low antral count, as no attempts had been done to either preserve her ovaries or an attempt on ivf and cryofreezing her embryos/eggs since she had an azoospermic husband or an IVM and now as expected her AMH showed loss of eggs although we took her for straight donor eggs after ensuring her ER status and PR status, with her having got tests for AMH outside and although she was having periods in view of her receiving multiple chemotherapeutic regimens followed by radiotherapy.After synchronizing her cycles with that of a donor we attempted donor egg ivf and inserted 2 grade A embryos with donor eggs as well as donor sperms but despite a good endometrium of $9.5 \mathrm{~mm}$ and negative EB PCR she did not conceive and after that she refused further treatment due to financial reasons.

\section{Discussion}

Although strongly positive for HER2 this patient was a good candidate for transztuzumab with CCT but due to its non-availability in India she received CCT along with brachytherapy. She had shown a good 5yr survival due to that. But since she was a case of primary infertility no attempt was done before starting her anti-cancer treatment with the modern approaches of trying to either cryopreserve her ovarian tissue [47-51] -or if not possible to slightly delay treatment and try a cycle of IVF and cryofreeze embryos [52] and transfer after patient has crossed 2-3 years of tumor free period/IVM treatment [53], which is the ideal treatment for patients receiving chemotherapy specially like cyclophosphamide which is known to accelerate development of POF, checking by AMH status [54] along with having teratogenic effects and further radiotherapy which is expected to knock off fertility as per protocols both by American College of oncologists as well as committee of the American Society of Reproductive Medicine (ASRM) [42,49]. Although legal issues have to be sorted out and ethical allowance restricts it in safe hands only [55].

\section{Reference}

1. American Cancer Society (2009) Cancer Facts \&Figures 2009, USA.

2. Surveillance, Epidemiology, and End Results program (2012) SEER ${ }^{\star S t a t}$ database (2013):Incidence.SEER 9registration research data.November2011submission, vintage 2009 population (1973-2009), USA.

3. Lang KJ, Berry SM, Powers GL, Beebe DJ, Alarid ET (2013) Hormonal responsive breast cancer cells in a microfluidic co-culture model as a sensor of microenvironment activity. Integr Biol 5: 807-16.

4. Akagi T, Kato K, Kobayashi M, Kosaka N, Ochiya T, et al. (2015) On Chip Immuno electrophoresis of extracellular vesicles released from human breast cancer cells. PLoS One10: e0123603.

5. Jeon JS, Bersini S, Gilardi M, Dubini G, Charest JL, et al. (2015) Human 3D vascularized organotypic microfluidic assays to study breast cancer extravasation. Proc Natl Acad Sci USA 112: 214-9.

6. Hayes DF, Cristofanilli M, Budd GT, Ellis M, Stopeck A, et al. (2006) Circulating tumor cells at each follow up time point during therapy of metastatic breast cancer patients predicts progression free and overall survival. Clin Cancer Res 12: 4218-24. 
7. Surveillance, Epidemiology, and End Results program (2012) Previous Version: SEER cancer Statistics review.1975-2009(vintage 2009 populations), USA.

8. Slamon D, Clark G, Wong S, Levin W, Ullrich A, et al. (1987) Human breast cancer: coorelation with relapse and survival with amplification of the HER-2/ neuoncogene. Science 235: 177-82.

9. Slamon D, Goddilphin W, Jones L, Holt J, Wong SG, et al. (1989) Studies of the HER2/neuprotooncogenein human breast and ovarian cancer. Science 244: 70712.

10. Slamon D, Leyland-Jones B, Shak S, Fuchs H, Paton V, et al. (2001) Use of chemotherapy plus a monoclonal antibody against HER2 for metastatic breast cancer that overexpresses HER2. N Engl J Med 344: 783-92.

11. Romand E, Perez E, Bryant J, Suman V, Geyer C Jr, et al. (2005) Tranztumab plus adjuvant chemotherapy for operable HER2 positive breast cancer. N Engl J Med 353:1673-84.

12. Perez EA, Romand EH, Suman VJ, Jeong JH, Davidson NE, et al. (2011) Four year follow up of transtuzumab plus adjuvant chemotherapy for operable human epidermal growth factor receptor 2 positive breast cancer: joint analysis of data from NCCTGN9831and NSAPB B-31. J Clin Oncol 29: $3366-73$.

13. Perez E, Romand E, Suman V, Jeong J, Sledge G, et al. (2014) Transtuzumab plus adjuvant chemotherapy for operable human epidermal growth factor receptor 2 positive breast cancers: planned joint analysis of overall survival from NSAPB B-31and NCCTGN9831. J Clin Oncol 32: $3744-52$.

14. Stagg J, Loi S, Divisekera U, Ngiow SF, Duret H, et al. (2011) Anti-ErbB-2 mAb therapy requires type I and II interferons and synergizes with anti-PD-1 or antiCD137 mAb therapy. Proc Natl Acad Sci USA108: 7142-7.

15. Manzoni M, Rovani B, Ronzoni M, Loupakis F, Mariucci S, et al. (2010) Immunological effects of bevacizumab-based treatments in metastatic colorectal cancer Oncology 79: 187-96.

16. Hodi F, Lawrwnce D, Lezcano C, Wu X, Zhou J, et al. (2014) Bevacizumab plus ipilimumabin patients with metastatic melanoma. Cancer Immunol Res 2: $632-42$.

17. Terme M, Perrot S, Marchetau E, Sandoval F, Benhaimouda N, et al. (2013) VEGFA-VEGFR pathway blockade inhibits tumor induced regulatory T cell proliferation in colorectal cancer. Cancer Res 73: 539-49.

18. Miller K, Wang M, Grallow J, Dickler M, Cobleigh M, et al. (2007) Paclitaxel plus bevacizumab vers is Paclitaxel alone for metastatic breast cancer. N Engl J Med 357: 2666-76

19. Szabo E (2003) MUC1 expression in lung cancer. Methods Mol Med 74: 251-8.

20. Brayman M, Thathiah A, Carson D (2004) MUC1: A multi-functional cell surface component of reproductive tissue epithelia. Reprod Biol Endocrinol 2: 4.

21. Kochar Kaur K, Allahbadia GN, Singh M (2016) Tacemotide-an immunotherapy for advanced cancers expressing mucin-is it reality for future elimination of advanced cancers-a Review. J Clin Immunotherapy.

22. Kimura T, Finn O (2013) MUC1 immunotherapy is here to stay. Expert Opin Biol Ther 13: 35-49.

23. De Gregario M, Wurz TG, Gutierrez A, Wolf M (2012) LBLP-25 vaccine plus Letrozole for breast cancer: is translation possible. Onco Immunol 1: 1422-4.

24. Mitchell K, Thircher N, Socinski M, Wasillewska-Tesluk L, Horwoodi K, et al. (2015) Tecemotide in unresectable stage III nonsmall cell lung cancer in the phase III START study: updated overall survival and biomarker analysis. Ann Oncol 26: 1134-42.

25. Wang M, Cao JX, Liu YS, Xu BL, Zhang XY, et al. (2015) Evaluation of tumour vaccine immunotherapy for the treatment of advanced non-small cell lung cancer: asystematic analysis. BMJ Open 5: e006321.

26. Kao CZ, Wurz GT, Lin YC, Vang DP, Griffey SM, et al. (2015) Assessing the effects of concurrent versus sequential cisplatin/radio therapy on immune status in lung tumor bearing C57BL/6mice. Cancer Immunol Res 3: 741-50.

27. Lu J, Leu-Gabel L, Nadaeu MC, Ferenz TM, Soiefel SA (2014) Clinical evaluation of compounds targeting PD1/PDL1 pathway for cancer immunotherapy. J Oncol Pharm Pract 21: 451-67.

28. Emens L, Brateh F, Cassier P, Delord J, Eder J, et al. (2015) Inhibition of PD-L1 by MPDL3280A leads to clinical activity in patients with metastatic triple negative breast cancer (TNBC) (Abstract 2859.). In Annual Meeting of the Am Ass Can Res Philadelphia, PA.

29. Sierro S, Romero P, Spieser DE (2011) The CD4-like molecule LAG-3, biology and -therapeutic applications. Expert Opin Ther Targets 15: 91-101.

30. Ngyen LT, Ohashi PS (2015) Clinical blockade of PD1 and LAG3-potential mechanisms of actions. Nat Rev Immunol 15: 45-56.

31. Goldberg MV, Drake CG (2011) LAG3 in cancer immunotherapy. Curr Top Microbiol Immunol 344: 269-78.

32. Brignone C, Gutierrez M, Mefti F, Brain E, Jarcau R, et al. (2010) First line chemo immunotherapy in metastatic breast carcinoma combination of paclitaxel and IMP321(LAG3Ig) enhance immune responses and antitumor activity. J Transl Med 8: 71.

33. Heery CR, Ibrahim NK, Arlen PM, Mohebtash M, Murray JL, et al. (2015) Docetaxelalone or in combination with a therapeutic cancer vaccine (PANVAC) in patients with metastatic breast cancer. A randomized clinical trial. JAMA Oncol 1: 1087-95.

34. Saadatmand S, de Kruijf EM, Sajet A, Dekker-Ensink NG, van Nes JG, et al. (2013) Expression of cell adhesion molecules and prognosis in breast cancer. Br J Surg 100: 252-60.

35. Jiang T, Sun Y, Yin Z, Feng S, Sun L, et al. (2015) Research progress of indoleamine 2,3 dioxygenase inhibitors. Future Med Chem T 7: 185-201.

36. Uyttenhove C, Pilotte L, Theate I, StroobantV, Colau D, et al. (2003) Evidence for a tumoral immune resistance mechanism based on tryptophan degradation by indoleamine 2,3 dioxygenase. Nat Med 9: 1269-74.

37. Soliman HH, Jackson E, Neuger T, Dees EC, Harvey RD, et al. (2014) A first in man phase I trial of immunomodulator, indoximod combined with docetaxelin patients with metastatic solid tumors. Oncotarget 5: 8136-46.

38. Ibrahim NK, Murray JL, Zhou D, Mittendorf EA, Sample D, et al. (2013) Survival advantage in petients with metastatic breast cancer receiving endocrine therapy plus SialylTn-KLH Vaccine: Post Hoc analysis of a large Randomized Trial. J Cancer 4: 577-84.

39. Soleimani R, Heytens E, Darzynkiewicz Z, Oktay K (2011) Mechanisms of chemotherapy induced human ovarian ageing:Double strand DNA breaks and micro vascular compromise. Aging (Albany,NY) 3: 782-93.

40. Ruddy KJ, Partridge AH (2012) The unique reproductive concepts of young women with breast cancer. Adv Exp Med Biol 732: 77-87.

41. Partridge AH, Gelber S, Peppercorn J, Ginsburg E, Sampson E, et al. (2008) Fertility and menopausal outcomes in young breast cancer survivors. Clin Breast Cancer 8: 65-9.

42. Hulvat MC, Jeruss JS (2011) Fertility preservation options for young women with breast cancer. Curr Opin Obstt Gynecol 23:174-82. 
43. Loren AW, Mangu PB, Beck LN, Brennan L, Magdalinski AJ, et al. (2013) Fertility preservation for patients with cancer: American Society of Oncologyclinical practiceguideline update. J Clin Oncol 31: 2500-10.

44. Oktay K, Sommerer M (2008) Chemotherapy and amenorrhea: Risks and treatments options. Curr Opin Obstt Gynecol 20: 408-15.

45. Ganz PA, Land SR, Geyer CE Jr, Cecchini RS, Costantino JP, et al. (2011) Menstrual history and quality of life outcome in wome nwith node -positive breast cancer treated with adjuvant therapy on NSABP-30 trial. J Clin Oncol 29:1110-6.

46. Abusief ME, Missmer SA, Ginsburg ES, Weeks JC, Partridge AH, et al. (2010) The effects of paclitaxel, dose density and transtuzumab on treatment related amenorrheain premenopausal women with breast cancer. Cancer 116: 791-8.

47. Lee S, Ozkavukcu S, Heytens E, Moy F, Oktay K (2010) Value of early referral to Fertility preservation in young women with Breast Cancer. J Clin Oncol 28: 4683-6.

48. Azim AA, Costantini-Ferrando M, Oktay K (2008) Safety of fertility preservation by ovarian stimulation with letrozole and gonadotrophins in patients with breast cancer: A prospectively controlled study. J Clin Oncol 26: 2630-5.

49. Courbiere B, Decanter C, Bringer-Deutsch S, Rives N, Mirallie S, et al. (2013) Emergency IVF for embryo freezing to preserve female fertility:a French multicentre cohort study. Hum Reprod 28: 2381-8.

50. Goldfarb SB, Kamer SA, Oppong BA, Eaton A, Patil S, et al. (2016) Fertility preservation for the young Breast Cancer Patient. Ann Surg Oncol 23: 1530-6.

51. Practice Committe of American Society of Reproductive Medicine: Society for Assisted Reproductive Technology. Mature oocyte cryopreservation: Aguideline. Fertil Steril 99: 37-43.

52. Jensen AK, Kristensen SG, Macklon KT, Jeppesen JV, Fedder J, et al. (2015) Outcomes of transplantations of cryopreserved ovarian tissue to 41women in Denmark. Hum Reprod 30: 2838-45.

53. Robertson DM, Gilchrist RB, Ledger WL, Baerwald A (2016) Random Start or Emergency IVF/in vitro maturation: A New Rapid approach to Fertility preservation. Women's Health (Lond Engl) 12: 339-49.

54. Anderson RA, Wallace WH (2013) Antimullerian Hormone, the assessment of the ovarian reserve, and the reproductive outcome of the young patient with cancer. Feril Steril 99: 1469-75.

55. Voultsos P, Raikos N, Vasileiadis N, Spiliopoulo Ch, Tarlatzis B (2016) Ethico-legal issues related to ovarian tissue transplantation. Med Sci Law 56: 293-304.

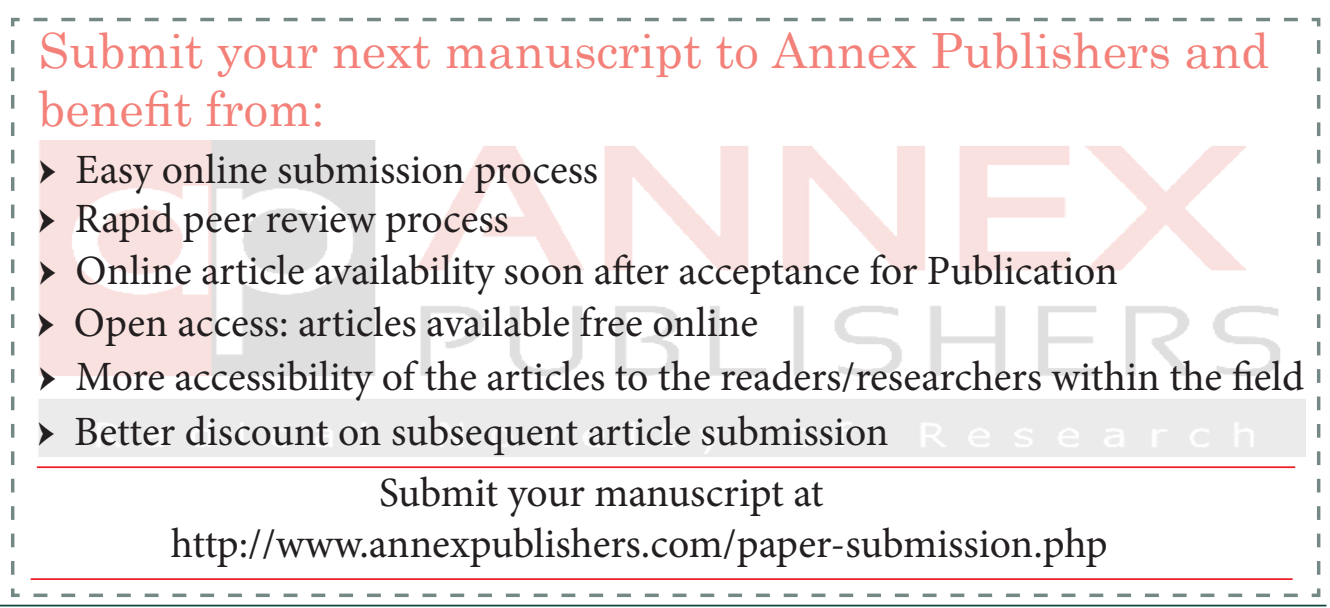

